\title{
Karakteristik Penderita Dispepsia Fungsional yang Mengalami Kekambuhan di Bagian IImu Penyakit Dalam RSUP Dr. M. Djamil Padang, Sumatera Barat Tahun 2011
}

\author{
Yui Muya ${ }^{1}$, Arina Widya Murni ${ }^{2}$, Rahmatina B. Herman ${ }^{3}$
}

\begin{abstract}
Abstrak
Dispepsia merupakan salah satu masalah kesehatan yang sering ditemui dokter dalam praktek sehari-hari. Prevalensi dispepsia fungsional di Inggris mencapai 23,8\%, sedangkan di Amerika Serikat 15\%. Di Indonesia belum terdapat prevalensi penyakit ini secara keseluruhan. Tujuan penelitian ini adalah untuk mengetahui karakteristik penderita dispepsia yang mengalami kekambuhan di RSUP Dr. M. Djamil Padang, Sumatera Barat tahun 2011. Penelitian ini bersifat deskriptif dengan desain cross sectional. Populasi sebanyak 63 data penderita tetapi sampel yang memenuhi syarat hanya 42 penderita. Proporsi tertinggi penderita dispepsia adalah kelompok umur 46-55 tahun $(38,1 \%)$, jenis kelamin perempuan $(64,3 \%)$, suku minang $(97,6 \%)$, agama Islam $(100 \%)$, tingkat pendidikan akademik/PT $(50,0 \%)$, pekerjaan ibu rumah tangga $(35,7 \%)$, dan status telah kawin $(71,4 \%)$. Kepada praktisi kesehatan atau dokter lini pertama agar dapat memaksimalkan usaha-usaha promosi kesehatan, sehingga masyarakat mendapat pengetahuan terutama mengenai sindrom dispepsia fungsional.
\end{abstract}

Kata kunci: dispepsia fungsional, karakteristik penderita, kekambuhan

\begin{abstract}
Dyspepsia is one of the common health problems that found by the doctors in daily practice. Prevalence rate of functional dyspepsia in the England is about $23.8 \%$ while in United Stated is about $15 \%$. In Indonesia, there has been no overall disease prevalence. The objective of this study was to investigate the characteristics of hospitalized patients with dyspepsia who have a relapse at Dr M. Djamil Hospital Padang, West Sumatra in 2011. This study uses descriptive cross sectional design. Population data were 63 patients but only 42 samples were taken. The highest proportion of dyspeptic patients was 46-55 years age group (38.1\%), female (64.3\%), ethnic Minang (97.6\%), Moslem (100\%), education level Academic (50.0\%), Housewife (35.7\%), and Married (71.4\%). Health practitioners or physician in order to maximize the health promotion efforts, so that people get the knowledge, especially regarding functional dyspepsia syndrome.
\end{abstract}

Keywords: functional dyspepsia, patient characteristics, relapsing

\begin{abstract}
Affiliasi penulis : : 1. Pendidikan Dokter FK UNAND (Fakultas Kedokteran Universitas Andalas Padang), 2. Bagian IImu Penyakit Dalam FK UNAND/RSUP Dr. M. Djamil Padang, 3. Bagian Fisiologi FK UNAND

Korespondensi :Yui Muya, E-mail: yuimuya@gmail.com, Telp: 085266484814
\end{abstract}

\section{PENDAHULUAN}

Salah satu penyakit tidak menular yang mempunyai angka kejadian tinggi di dunia adalah dispepsia. Dispepsia merupakan salah satu masalah kesehatan yang sering ditemui pada praktek seharihari. Diperkirakan hampir 30\% kasus yang dijumpai pada praktek umum dan $60 \%$ pada praktek gastroenterologi merupakan dispepsia. Dari data pustaka Negara Barat didapatkan angka prevalensinya berkisar $7-41 \%$, tapi hanya $10-20 \%$ 
yang mencari pertolongan. ${ }^{1}$

Data mengenai prevalensi dispepsia fungsional sangat beragam pada berbagai populasi. Data tersebut mungkin menunjukkan perbedaan epidemiologi dari berbagai wilayah. Pada suatu survei yang dilakukan oleh Shaib dan El-Serag pada pegawai dalam suatu institusi di Amerika Serikat, dengan melakukan pemeriksaan endoskopi mereka mendapatkan prevalensi dispepsia fungsional sebanyak $15 \%{ }^{2}$ Dua penelitian yang terpisah dilakukan di Inggris untuk menentukan prevalensi dispepsia fungsional, penelitian oleh Jones et al menggunakan barium enema dan endoskopi pada seperlima dari 9936 subjek mendapatkan prevalensi dispepsia fungsional sekitar 23,8\%, penelitian sebelumnya oleh Jones dan Lydeard pada $20 \%$ dari 2066 orang dewasa, diperkirakan $11,5 \%$ mengalami dispepsia fungsional., ${ }^{3,4} \mathrm{Di}$ Iceland dalam suatu penelitian populasi selama 10 tahun, terdapat peningkatan dari $13,9 \%$ di tahun 1996 menjadi 16,7\% di tahun $2006 .{ }^{5}$ Di Norwegia $14 \%$ dari 2027 orang dewasa juga mengalami dispepsia fungsional setelah diperiksa. $^{6} \mathrm{Di}$ Jepang, didapatkan $17 \%$ prevalensi dispepsia fungsional pada sebuah program skrining kanker lambung. ${ }^{7}$ Penelitian terhadap dispepsia fungsional di beberapa negara di Asia juga menunjukkan prevalensi yang cukup tinggi, yaitu Cina sebanyak 69\% dari 782 pasien dispepsia, di Hongkong $43 \%$ dari 1.353 pasien, di Korea $70 \%$ dari 476 pasien, dan Malaysia 62\% dari 210 pasien yang diperiksa. ${ }^{8} \mathrm{Di}$ Indonesia, angka prevalensi dispepsia fungsional secara keseluruhan belum ada hingga saat ini. Pada tahun 1991 di RS Cipto Mangunkusumo, terdapat $44 \%$ kasus dispepsia fungsional dari 52 pasien dispepsia yang menjalani pemeriksaan endoskopi. ${ }^{9}$ Harahap pada penelitian di RS Martha Friska Medan tahun 2007 mendapatkan dispepsia fungsional sebanyak 78,8\% dari 203 pasien yang diperiksa. ${ }^{10}$

Penderita dispepsia fungsional dapat terjadi pada berbagai rentang umur, jenis kelamin, etnik/suku, kondisi sosio-ekonomi. Hasil berbagai survei belum dapat menunjukkan prevalensi umur pasti untuk dispepsia fungsional. Dalam beberapa penelitian di Asia, dispepsia fungsional lebih sering dijumpai pada kelompok umur yang lebih muda, di Jepang prevalensinya $13 \%$ dan $8 \%$ untuk kelompok umur dibawah dan diatas 50 tahun, di Cina prevalensi terbanyak pada kisaran umur 41-50 tahun, dan di Mumbai, India terbanyak pada umur $>40$ tahun. ${ }^{11} \mathrm{Di}$ Indonesia, prevalensi terbanyak pada umur $\leq 40$ tahun yaitu $85 \%$, penelitian lain mendapatkan prevalensi terbanyak pada kisaran umur 26-35 tahun sebanyak $50 \%{ }^{12,13}$

Mayoritas penelitian mengenai prevalensi berdasarkan jenis kelamin tidak menunjukkan perbedaan yang signifikan antara pria dan wanita. Beberapa penelitian yang dilakukan dalam beberapa populasi hasilnya menunjukkan perbandingan wanita lebih banyak menderita dispepsia fungsional daripada laki-laki yaitu 1,4:1 di Hongkong, 1,12:1,04 di Korea, 1,35:1,15 di Malaysia dan 1,16:1,01 di Singapura. ${ }^{11}$ Namun, suatu penelitian di Jepang menunjukkan perbandingan prevalensi lebih besar pada laki-laki daripada wanita yaitu 2:1. ${ }^{8}$ Penelitian mengenai etnik juga pernah dilakukan, dua penelitian yang dilakukan di Malaysia menemukan prevalensi dispepsia fungsional pada suku Melayu 14,6\%, Cina 19,7\%, India 11,2\%dan lebih umum dijumpai pada etnis China dibandingkan non-China $\quad(19,7 \%$ berbanding 14,2\%). ${ }^{8,11}$ Penelitian di Medan menunjukkan prevalensi terbesar pada suku Batak $45,5 \%$, menyusul Karo $27,3 \%$, Jawa $18,2 \%$, dan yang terkecil Melayu $4,5 \%$ serta Mandailing 4,5\%. ${ }^{13}$

Faktor sosio-ekonomi juga pernah diteliti dalam berbagai penelitian berbasis-populasi, penelitian Drossman dkk. di Amerika Serikat menemukan hubungan yang kuat antara pendapatan rendah dengan kejadian gangguan saluran pencernaan fungsional termasuk dispepsia fungsional. ${ }^{14}$ Hasil serupa didapatkan di Cina, bahwa dispepsia fungsional berhubungan dengan ketidakpuasan terhadap pendapatan. ${ }^{11}$ Murni menyebutkan adanya hubungan pengalaman pada masa kecil, stresor yang dihadapi sepanjang hidup sampai usia dewasa serta dukungan sosial mempengaruhi respon fisiologis dan psikologis seseorang termasuk distress, kelainan psikiatri, agama serta mekanisme adaptasi (coping). ${ }^{15}$

Kekambuhan penyakit dispepsia fungsional merupakan masalah yang tidak fatal, tapi keluhan penderita sangat mengganggu kegiatan sehari-hari. ${ }^{16}$ 
Lebih dari $50 \%$ pasien dispepsia fungsional berada dalam masa pengobatan sepanjang waktu, pengeluaran biaya untuk pengobatan tidak sedikit dan kira-kira 30\% pasien dilaporkan mengambil libur dalam bekerja dan sekolah akibat dari kekambuhan gejala penyakit, sehingga menurunkan kualitas hidup. Stress psikologis merupakan salah satu faktor resiko yang sering menjadi pencetus kekambuhan dispepsia, termasuk didalamnya kecemasan, hipersensitivitas dan neurotisme. ${ }^{16,17}$

Angka kejadian penyakit dispepsia fungsional yang tinggi di dunia bahkan di Indonesia, serta masih minimnya data mendalam tentang dispepsia fungsional di Sumatera Barat, maka perlu dilakukan penelitian lebih lanjut tentang dispepsia fungsional. Penelitian ini lebih difokuskan pada karakteristik penderita dispepsia fungsional (umur, jenis kelamin, suku, agama, tingkat pendidikan, pekerjaan dan status perkawinan) yang mengalami kekambuhan. Penelitian dilakukan di RSUP Dr. M. Djamil dengan sampel berupa data penderita dispepsia fungsional yang berobat di Bagian IImu Penyakit Dalam dan pernah menjalani pemeriksaan endoskopi di Instalasi Diagnostik Terpadu (IDT) selama tahun 2011.

\section{METODE}

Penelitian ini dilakukan mulai April 2012 - Juni 2013 dengan mengambil data dari catatan medis pasien yang memeriksakan diri di bagian endoskopi RSUP Dr. M. Djamil tahun 2011. Penderita yang pernah berobat di Poliklinik Gastroenterology unit rawat jalan RSUP Dr. M. Djamil Padang, Sumatera Barat dengan keluhan dan hasil endoskopi sesuai dengan sindroma dispepsia fungsional sepanjang tahun 2011. Data didapatkan dari jumlah penderita yang ditemukan berobat di poliklinik penyakit dalam RSUP Dr. M. Djamil Padang dan memeriksakan diri di bagian Endoskopi RSUP Dr. M. Djamil Padang selama tahun 2011. Jenis penelitian yang digunakan adalah cross-sectional study. Variabel adalah umur, jenis kelamin, suku, agama, tingkat pendidikan, pekerjaan dan status perkawinan. Alat yang digunakan adalah catatan hasil pengambilan data rekam medik.
Tabel 1. Distribusi frekuensi subjek penelitian berdasarkan umur, suku, agama, pendidikan, pekerjaan dan status perkawinan

\begin{tabular}{|c|c|c|c|}
\hline \multicolumn{2}{|c|}{ Karakteristik } & $\begin{array}{c}\text { Frekuensi } \\
\text { (n) }\end{array}$ & $\begin{array}{c}\text { Persentase } \\
(\%)\end{array}$ \\
\hline \multirow{5}{*}{ Umur } & 17-25th & 3 & 7,1 \\
\hline & $26-35$ th & 3 & 7,1 \\
\hline & $36-45$ th & 11 & 26,2 \\
\hline & $46-55$ th & 16 & 38,1 \\
\hline & $56-65$ th & 9 & 21,4 \\
\hline \multirow{4}{*}{$\begin{array}{l}\text { Jenis } \\
\text { Kelamin }\end{array}$} & Total & 42 & 100 \\
\hline & Laki-Laki & 15 & 35,7 \\
\hline & Perempuan & 27 & 64,3 \\
\hline & Total & 42 & 100 \\
\hline \multirow{6}{*}{ Suku } & Minang & 41 & 97,6 \\
\hline & Batak & 0 & 0 \\
\hline & Jawa & 1 & 2,4 \\
\hline & Melayu & 0 & 0 \\
\hline & Aceh & 0 & 0 \\
\hline & Tionghoa & 0 & 0 \\
\hline \multirow{7}{*}{ Agama } & Total & 42 & 100 \\
\hline & Islam & 42 & 100 \\
\hline & Kristen & 0 & 0 \\
\hline & Protestan & & \\
\hline & Kristen Katolik & 0 & 0 \\
\hline & Hindu & 0 & 0 \\
\hline & Buddha & 0 & 0 \\
\hline \multirow{6}{*}{ Pendidikan } & Total & 42 & 100 \\
\hline & Tidak Sekolah & 0 & 0 \\
\hline & Sd/Sederajat & 3 & 7,1 \\
\hline & Smp/Sederajat & 4 & 9,5 \\
\hline & Sma/Sederajat & 14 & 33,3 \\
\hline & Akademik/Pt & 21 & 50,0 \\
\hline \multirow{8}{*}{ Pekerjaan } & Total & 42 & 100 \\
\hline & IRT & 15 & 35,7 \\
\hline & PNS & 13 & 31 \\
\hline & Swasta & 5 & 11,9 \\
\hline & Pelajar & 3 & 7,1 \\
\hline & Pengangguran & 0 & 0 \\
\hline & Pensiun & 6 & 14,3 \\
\hline & Lain-Lain & 0 & 0 \\
\hline \multirow{4}{*}{$\begin{array}{l}\text { Status } \\
\text { Perkawinan }\end{array}$} & Total & 42 & 100 \\
\hline & Kawin & 30 & 71,44 \\
\hline & Belum Kawin & 3 & 7,1 \\
\hline & Janda/Duda & 9 & 21,4 \\
\hline & Total & 42 & 100 \\
\hline
\end{tabular}




\section{HASIL DAN PEMBAHASAN}

Tabel 2 memperlihatkan status kekambuhan dispepsia fungsional yaitu sering sebanyak 25 orang $(59,5 \%)$ dan jarang sebanyak 17 orang (40,5\%).

Tabel 2. Distribusi Frekuensi Subjek Penelitian Berdasarkan Status Kekambuhan

\begin{tabular}{ccc}
\hline Kekambuhan & $\begin{array}{c}\text { Frekuensi } \\
\text { (n) }\end{array}$ & $\begin{array}{c}\text { Persentase } \\
\text { (\%) }\end{array}$ \\
\hline Jarang & 17 & 40,5 \\
Sering & 25 & 59,5 \\
\hline Total & 42 & 100 \\
\hline
\end{tabular}

Tabel 3 menggambarkan status kekambuhan dispepsia fungsional yaitu frekuensi sering terbanyak pada umur 46-55 tahun yaitu sebanyak 9 orang $(21,4 \%)$ dan frekuensi jarang terbanyak juga pada umur 46-55 tahun yaitu sebanyak 17 orang (16,7\%).

Angka tertinggi berada pada kisaran 46-55 tahun, tetapi perbedaan hasil antara kekambuhan sering dan jarang tidak terlalu signifikan. Data tersebut mungkin disebabkan oleh beragam faktor-faktor resiko yang mempengaruhi penderita tingkat kekambuhan dispepsia fungsional, misalnya aktivitas olahraga efektif meningkatkan kemampuan manajemen stress, merangsang peningkatan sistem imum terhadap $H$. pylory, membantu seseorang bertahan terhadap stres, dan mereduksi rangsangan sekresi asam lambung. ${ }^{17}$ Selain itu faktor hormonal juga dapat dipertimbangkan menjadi faktor resiko. Dalam beberapa percobaan, progesteron, estradiol dan prolaktin mempengaruhi kontraktilitas otot polos dan memperlambat waktu transit gastrointestinal. ${ }^{1}$ Pertambahan umur seseorang seringkali dihubungkan dengan penurunan aktivitas olahraga rutin dan penurunan aktivitas hormonal fisiologis seseorang, hal ini mungkin menyebabkan meningkatnya resiko kekambuhan dispepsia fungsional.

Tabel 4 menggambarkan status kekambuhan dispepsia fungsional yaitu frekuensi sering terbanyak pada jenis kelamin perempuan yaitu sebanyak 16 orang $(38,1 \%)$ dan frekuensi jarang terbanyak juga pada jenis kelamin perempuan yaitu sebanyak 11 orang $(26,2 \%)$.

Tabel 3. Distribusi frekuensi subjek penelitian berdasarkan status kekambuhan dan umur

\begin{tabular}{cccccc}
\hline & \multicolumn{4}{c}{ Kekambuhan } \\
\cline { 3 - 6 } & & \multicolumn{2}{c}{ Sering } & \multicolumn{2}{c}{ Jarang } \\
\cline { 3 - 6 } & & (n) & (\%) & (n) & $(\%)$ \\
\hline \multirow{4}{*}{ Umur } & 17-25th & 2 & 4,8 & 1 & 2,4 \\
& $26-35$ th & 2 & 4,8 & 1 & 2,4 \\
& 36-45 th & 8 & 19 & 3 & 7,1 \\
& $46-55$ th & 9 & 21,4 & 7 & 16,7 \\
& $56-65$ th & 4 & 9,5 & 5 & 11,9 \\
\hline total & & 25 & 59,5 & 17 & 40,5 \\
\hline
\end{tabular}

Berdasarkan penelitian ini, tingkat kekambuhan tidak berhubungan dengan perbedaan jenis kelamin, tetapi lebih berhubungan dengan prevalensi jenis kelamin tertentu. Pada tabel 4 terlihat angka tertinggi berada pada jenis kelamin wanita, tetapi perbedaan hasil antara kekambuhan sering dan jarang tidak terlalu signifikan.

Tabel 4. Distribusi frekuensi subjek penelitian berdasarkan status kekambuhan dan jenis kelamin

\begin{tabular}{cccccc}
\hline & & \multicolumn{3}{c}{ Kekambuhan } \\
\cline { 3 - 6 } & & \multicolumn{2}{c}{ Sering } & \multicolumn{2}{c}{ Jarang } \\
\cline { 3 - 6 } & & $\mathbf{( n )}$ & $\mathbf{( \% )}$ & $\mathbf{( n )}$ & $(\%)$ \\
\hline \multirow{2}{*}{$\begin{array}{c}\text { Jenis } \\
\text { Kelamin }\end{array}$} & Laki-Laki & 9 & 21,4 & 6 & 14,3 \\
& Perempuan & 16 & 38,1 & 11 & 26,2 \\
\hline \multicolumn{2}{c}{ Total } & 25 & 59,5 & 17 & 40,5 \\
\hline
\end{tabular}

Pada tabel 5 dapat dilihat bahwa proporsi penderita yang sering maupun jarang mengalami kekambuhan, lebih tinggi pada kelompok suku Minang yaitu sebesar $57,1 \%$ dan 40,5\%. Hasil ini bukan karena suku Minang beresiko untuk menderita dispepsia fungsional namun erat kaitannya dengan jumlah pengunjung yang datang berobat ke bagian Ilmu Penyakit Dalam RSUP Dr. M. Djamil Padang paling banyak adalah suku Minang. 
Tabel 5. Distribusi frekuensi subjek penelitian berdasarkan status kekambuhan dan suku

\begin{tabular}{clcccc}
\hline & \multicolumn{4}{c}{ Kekambuhan } \\
\cline { 3 - 6 } & & \multicolumn{2}{c}{ Sering } & \multicolumn{2}{c}{ Jarang } \\
\cline { 2 - 6 } & (n) & $(\%)$ & (n) & $(\%)$ \\
\hline \multirow{6}{*}{ Suku } & Minang & 24 & 57,1 & 17 & 40,5 \\
& Batak & 0 & 0 & 0 & 0 \\
& Jawa & 1 & 2,4 & 0 & 0 \\
& Melayu & 0 & 0 & 0 & 0 \\
& Aceh & 0 & 0 & 0 & 0 \\
& Tionghoa & 0 & 0 & 0 & 0 \\
\hline Total & & 25 & 59,5 & 17 & 40,5 \\
\hline
\end{tabular}

Pada tabel 6 dapat dilihat bahwa proporsi penderita yang sering maupun jarang mengalami kekambuhan, lebih tinggi pada kelompok agama Islam yaitu sebesar 59,5\% dan 40,5\%. Hasil ini bukan karena agama Islam beresiko untuk menderita dispepsia fungsional namun erat kaitannya dengan jumlah pengunjung yang datang berobat ke bagian IImu Penyakit Dalam RSUP Dr. M. Djamil Padang paling banyak adalah seorang Muslim.

Tabel 6. Distribusi frekuensi subjek penelitian berdasarkan status kekambuhan dan agama

\begin{tabular}{lcccc}
\hline \multirow{2}{*}{ Agama } & \multicolumn{4}{c}{ Kekambuhan } \\
\cline { 2 - 5 } & \multicolumn{2}{c}{ Sering } & \multicolumn{2}{c}{ Jarang } \\
\cline { 2 - 5 } & (n) & (\%) & (n) & $(\%)$ \\
\hline Islam & 25 & 59,5 & 17 & 40,5 \\
Kristen & 0 & 0 & 0 & 0 \\
Protestan & & & & \\
Kristen & 0 & 0 & 0 & 0 \\
Katolik & 0 & 0 & 0 & 0 \\
Hindu & 0 & 0 & 0 & 0 \\
Buddha & 0 & 59,5 & 17 & 40,5 \\
\hline Total & 25 & &
\end{tabular}

Tabel 7 menunjukkan proporsi penderita yang sering mengalami kekambuhan, lebih tinggi pada kelompok tingkat pendidikan akademik/PT yaitu sebesar 23,8\% sedankan untuk proporsi kekambuhan penyakit jarang terdapat pada tingkat pendidikan SMA/sederajat dan akademik/PT yaitu sebesar $26,2 \%$. Pada tabel 7 terlihat frekuensi penderita tertinggi berada pada akademik/PT, tetapi perbedaan hasil tidak terlalu signifikan.
Tabel 7. Distribusi frekuensi subjek penelitian berdasarkan status kekambuhan dan tingkat pendidikan

\begin{tabular}{lccccc}
\hline \multirow{3}{*}{ Pendidikan } & \multicolumn{3}{c}{ Kekambuhan } & \\
\cline { 2 - 4 } & \multicolumn{3}{c}{ Sering } & \multicolumn{3}{c}{ Jarang } & \\
\cline { 2 - 4 } & $\mathbf{( n )}$ & $\mathbf{( \% )}$ & $\mathbf{( n )}$ & \\
\hline Tidak sekolah & 0 & 0 & 0 & 0 \\
SD/sederajat & 2 & 4,8 & 1 & 2,4 \\
SMP/sederajat & 2 & 4,8 & 2 & 4,8 \\
SMA/sederajat & 3 & 7,1 & 11 & 26,2 \\
Akademik/PT & 10 & 23,8 & 11 & 26,2 \\
\hline Total & 17 & 59,5 & 25 & 40,5 \\
\hline
\end{tabular}

. Data tersebut mungkin disebabkan karena faktor resiko yang mempengaruhi, misalnya stres psikologis pada penderita dengan tingkat pendidikan akademik/PT lebih besar karena biasanya penderita yang mempunyai pendidikan tinggi mempunyai pekerjaan yang cenderung lebih berat dibandingkan penderita dengan pendidikan menengah kebawah. Hal ini mungkin menyebabkan stres psikologis yang lebih besar dibandingkan tingkat pendidikan yang lebih rendah.

Tabel 8. Distribusi frekuensi subjek penelitian berdasarkan status kekambuhan dan pekerjaan

\begin{tabular}{lcccc}
\hline \multirow{2}{*}{ Pekerjaan } & \multicolumn{4}{c}{ Kekambuhan } \\
\cline { 2 - 5 } & \multicolumn{2}{c}{ Sering } & \multicolumn{2}{c}{ Jarang } \\
\cline { 2 - 5 } & (n) & (\%) & (n) & (\%) \\
\hline lbu Rumah & 10 & 23,8 & 5 & 11,9 \\
Tangga & 8 & 19 & 5 & 11,9 \\
PNS & 2 & 4,8 & 3 & 7,1 \\
Swasta & 2 & 4,8 & 1 & 2,4 \\
Pelajar/mahasiswa & 0 & 0 & 0 & 0 \\
Pengangguran & 3 & 7,1 & 3 & 7,1 \\
Pensiun & 0 & 0 & 0 & 0 \\
Lain-lain & 25 & 59,5 & 17 & 40,5 \\
\hline Total & & & \multicolumn{1}{c}{}
\end{tabular}

Pada Tabel 8 dapat dilihat bahwa proporsi penderita yang sering mengalami kekambuhan, lebih tinggi pada kelompok pekerjaan IRT yaitu sebesar $23,8 \%$ sedangkan untuk proporsi kekambuhan penyakit jarang terdapat pada pekerjaan swasta dan pensiunan yaitu masing-masing sebesar 7,1\%. 
Tabel 9. Distribusi frekuensi subjek penelitian berdasarkan status kekambuhan dan status perkawinan

\begin{tabular}{lcccc}
\hline \multirow{2}{*}{$\begin{array}{c}\text { Status } \\
\text { Perkawinan }\end{array}$} & \multicolumn{4}{c}{ Kekambuhan } \\
\cline { 2 - 5 } & Sering & \multicolumn{2}{c}{ Jarang } \\
\cline { 2 - 5 } & (n) & $(\%)$ & (n) & $(\%)$ \\
\hline Kawin & 20 & 47,6 & 10 & 23,8 \\
Belum Kawin & 2 & 4,8 & 1 & 2,4 \\
Janda/Duda & 3 & 7,1 & 6 & 14,3 \\
\hline Total & 25 & 59,5 & 17 & 40,5 \\
\hline
\end{tabular}

Pada Tabel 8 terlihat frekuensi tingkat kekambuhan sering tertinggi berada pada pekerjaan IRT. Data tersebut mungkin disebabkan karena faktor resiko yang mempengaruhi, misalnya stres psikologis akibat aktivitas yang monoton meningkatkan tingkat kejenuhan sehingga menimbulkan stres dan depresi, sehingga secara tidak langsung meningkatkan resiko terjadinya dispepsia fungsional. ${ }^{13}$

Pada Tabel 9 dapat dilihat bahwa proporsi penderita yang sering maupun jarang mengalami kekambuhan, lebih tinggi pada kelompok status kawin yaitu sebesar $46,7 \%$ dan $23,8 \%$.

\section{KESIMPULAN}

Karakteristik penderita dispepsia fungsional yang mengalami kekambuhan di bagian ilmu penyakit dalam RSUP Dr. M. Djamil Padang, Sumatera Barat yang paling banyak pada kelompok umur 46-55 tahun, jenis kelamin perempuan, suku Minang , agama Islam, tingkat pendidikan Akademik/PT, pekerjaan Ibu Rumah Tangga dan status telah kawin.

Proporsi tingkat kekambuhan dispepsia fungsional tertinggi menurut umur yaitu frekuensi sering terbanyak pada umur 46-55 tahun.

Proporsi tingkat kekambuhan dispepsia fungsional tertinggi menurut jenis kelamin yaitu frekuensi sering terbanyak pada wanita.

Proporsi tingkat kekambuhan dispepsia fungsional tertinggi menurut suku yaitu frekuensi sering terbanyak pada suku Minang.

Proporsi tingkat kekambuhan dispepsia fungsional tertinggi menurut agama yaitu frekuensi sering terbanyak pada agama Islam.

Proporsi tingkat kekambuhan dispepsia fungsional tertinggi menurut tingkat pendidikan yaitu frekuensi sering terbanyak pada tingkat pendidikan Akademik/PT (23,8\%).

Proporsi tingkat kekambuhan dispepsia fungsional tertinggi menurut tingkat pendidikan yaitu frekuensi sering terbanyak pada pekerjaan Ibu Rumah Tangga (23,8\%).

Proporsi tingkat kekambuhan dispepsia fungsional tertinggi menurut status perkawinan yaitu frekuensi sering terbanyak pada status kawin $(47,6 \%)$.

\section{UCAPAN TERIMA KASIH}

Penulis mengucapkan terima kasih kepada respondensi dan pihak-pihak yang terlibat dalam pengolahan data.

\section{DAFTAR PUSTAKA}

1. Djojoningrat D. Dispepsia fungsional. Buku Ajar IImu Penyakit Dalam. Edisi ke-5. Jakarta: Balai Penerbit FK UI. 2009.hlm. 529-32.

2. Shaib Y, El-Serag HB. Prevalence and risk factors of functional dyspepsia. American Journal of Gastroenterology. 2004; 99(11).

3. Jones RH, Lydeard SE, Hobbs FD, Kenkre JE, Williams El, Jones SJ, et al. Dyspepsia in England and Scotland. Gut. 1990;31:401-5.

4. Jones R, Lydeard S. Prevalence of symptoms of dyspepsia in the community. BMJ. 1989;298:30-2.

5. Olafsdottir LB, Gudjonsson $\mathrm{H}$, Jonsdottir $\mathrm{HH}$, Thjodleifsson B. Natural history of functional dyspepsia: a 10-year population-based study. Pubmed. 2010;81(1):53-61.

6. Bernersen B, Johnsen R, Straume B. Non-ulcer dyspepsia and peptic ulcer: the distribution in a population and their relation to risk factor. Gut. 1996;38:822-5.

7. Mahadeva S, Goh KL. Epidemiology of functional dyspepsia: a global perspective. Pubmed. 2006;12(17): 2661-6.

8. Goshal UC, Singh R, Chang F, Hou X, Wong B. CY, Kachintorn U. Epidemiology of uninvestigated and functional dyspepsia in Asia: fact and fiction. JNM. 2011;17(3).

9. Mudjaddid E. Dispepsia fungsional. Buku Ajar : IImu Penyakit Dalam. Edisi ke-5. Jakarta: Balai Penerbit FK UI; 2009. hlm.2109-10. 
10. Harahap Y. Karakteristik penderita dispepsia rawat inap di RS Martha Friska Medan tahun 2007 (skripsi). Medan: Fakultas Kesehatan Masyarakat; 2009.

11. Kumar A, Jignesh P, Prabha S. Epidemiology of functional dyspepsia. J Assoc Physicians India. 2012;60 suppl: 9-12.
12. Harahap HS. Karakteristik pasien dispepsia yang rawat inap di rumah sakit umum Sundari Medan Tahun 2008 (skripsi). Medan: Fakultas Kesehatan Masyarakat Medan; 2010.

13. Tarigan C. Perbedaan depresi pada pasien dispepsia fungsional dan dispepsia organik (tesis). Medan: Universitas Sumatera Utara. 2001. 